\title{
Feeling body dissatisfied after viewing thin-ideal pictures is mediated by self-activation
}

Citation for published version (APA):

Smeets, E., Jansen, A. T. M., Vossen, E., Ruf, L., \& Roefs, A. J. (2010). Feeling body dissatisfied after viewing thin-ideal pictures is mediated by self-activation. Body Image, 7(4), 335-340.

https://doi.org/10.1016/j.bodyim.2010.07.001

Document status and date:

Published: 01/09/2010

DOI:

10.1016/j.bodyim.2010.07.001

Document Version:

Publisher's PDF, also known as Version of record

Document license:

Taverne

Please check the document version of this publication:

- A submitted manuscript is the version of the article upon submission and before peer-review. There can be important differences between the submitted version and the official published version of record.

People interested in the research are advised to contact the author for the final version of the publication, or visit the DOI to the publisher's website.

- The final author version and the galley proof are versions of the publication after peer review.

- The final published version features the final layout of the paper including the volume, issue and page numbers.

Link to publication

\footnotetext{
General rights rights.

- You may freely distribute the URL identifying the publication in the public portal. please follow below link for the End User Agreement:

www.umlib.nl/taverne-license

Take down policy

If you believe that this document breaches copyright please contact us at:

repository@maastrichtuniversity.nl

providing details and we will investigate your claim.
}

Copyright and moral rights for the publications made accessible in the public portal are retained by the authors and/or other copyright owners and it is a condition of accessing publications that users recognise and abide by the legal requirements associated with these

- Users may download and print one copy of any publication from the public portal for the purpose of private study or research.

- You may not further distribute the material or use it for any profit-making activity or commercial gain

If the publication is distributed under the terms of Article $25 \mathrm{fa}$ of the Dutch Copyright Act, indicated by the "Taverne" license above, 


\title{
Feeling body dissatisfied after viewing thin-ideal pictures is mediated by self-activation
}

\author{
Elke Smeets *, Anita Jansen, Ellis Vossen, Laura Ruf, Anne Roefs \\ Maastricht University, Department of Clinical Psychological Science, Maastricht, The Netherlands
}

\section{A R T I C L E I N F O}

\section{Article history:}

Received 5 October 2009

Received in revised form 5 July 2010

Accepted 16 July 2010

\section{Keywords:}

Self-activation

Social comparison

Body dissatisfaction

Restrained eaters

Media exposure

\begin{abstract}
A B S T R A C T
The present study sought to investigate the influence of self-activation on body and weight satisfaction in restrained and unrestrained eaters, after exposure to thin-ideal images. Restrained eaters $(n=39)$ and unrestrained eaters $(n=40)$ were randomly assigned to a self-activation manipulation versus a control manipulation. After the manipulation, all participants were exposed to eight thin-ideal images. Measures of state body and weight satisfaction and of social comparison tendencies were assessed throughout the experiment. Self-activated restrained eaters showed a significant decrease in body and weight satisfaction after exposure to thin-ideal images, compared to restrained eaters who were not selfactivated. In unrestrained eaters, the self-activation manipulation did not have any effect on body or weight dissatisfaction. In conclusion, exposure to fashion models only had a negative influence on women's self-evaluations when two conditions were met: (1) the participant was 'self-activated' and (2) the participant classified as a restrained eater.
\end{abstract}

(c) 2010 Elsevier Ltd. All rights reserved.

\section{Introduction}

It is a commonly held belief that the media's focus on slenderness and beauty affects women adversely. By setting an unrealistic beauty standard, the media have been considered to promote feelings of body dissatisfaction in many women. Indeed, this belief seems to be supported by two meta-analyses (Grabe, Ward, \& Hyde, 2008; Groesz, Levine, \& Murnen, 2002) which consistently found support for the detrimental effects of thin-ideal exposure on the way women feel about their body.

Nevertheless, as we consider the percentages of body dissatisfaction in our society (25-50\%; Bearman, Presnell, Martinez, \& Stice, 2006; Stice \& Whitenton, 2002), it seems that not all women react in the same negative way to media-portrayed idealized body images. This can be explained by certain individual differences that might cause some women to be more vulnerable to the effects of the media than others. More specifically, research has shown that women who have higher dispositional levels of body dissatisfaction (Posavac, Posavac, \& Posavac, 1998; Trampe, Stapel, \& Siero, 2007), and women who invest more in beauty and thinness (e.g., thin-ideal internalization; Dittmar \& Howard, 2004; Stice \& Whitenton, 2002) are more likely to be affected adversely than other women. Another

\footnotetext{
* Corresponding author at: Faculty of Psychology, Clinical Psychological Science, Maastricht University, P.O. Box 616, 6200 MD Maastricht, The Netherlands Tel.: +31 43 3884325; fax: +31433884196.

E-mail address: elke.smeets@maastrichtuniversity.nl (E. Smeets).
}

individual difference variable that has been found to make women more vulnerable to the adverse effects of the media, is the tendency to compare one's appearance to that of other women (Cattarin, Thompson, Thomas, \& Williams, 2000; Dittmar \& Howard, 2004; Tiggemann \& McGill, 2004). Indeed social comparison (Festinger, 1954) has been generally considered an important variable in explaining women's adverse reactions to thin-ideal images. Women who regularly make self-comparisons to images of idealized women's bodies have been found to feel less attractive and more dissatisfied with their own body (Stice, Schupak-Neuberg, Shaw, \& Stein, 1994; Stormer \& Thompson, 1996) than other women. In addition, Corning, Krumm, and Smitham (2006) indicated that a greater tendency to engage in upward social comparison (i.e., in which the comparison target is perceived as better looking) predicts the presence of eating disorder symptoms.

Even though it is clear that the increased tendency to engage in social comparison is associated with feelings of body dissatisfaction, it is unclear where this tendency stems from in the first place. As yet, there has been very little research to address why some women have a higher need for social comparison than others. Investigating the mechanisms that drive women to compare their own appearance with that of others, Trampe et al. (2007) showed that body dissatisfaction is an important determinant in the occurrence of social comparison effects. In explaining this finding the authors hypothesize that body dissatisfied women are more likely to engage in social comparison because their self-related cognitions and feelings are more accessible (i.e., higher levels of self-activation) and because they consider a wider range of 
comparison targets as relevant (i.e., peers and fashion models). In this perspective, recent research from the field of social psychology has shown that self-activation is an important prerequisite for promoting social comparison tendencies (Stapel \& Tesser, 2001). Self-activation refers to a state in which one is more aware of one's self-related cognitions, feelings, behaviour and goals (like for example the goal of losing weight). Stapel and Tesser (2001) manipulated self-activation by instructing participants to name either four defining things about themselves (i.e., self-activation condition) or about a movie (i.e., control condition). Results indicated that participants in the self-activation condition showed higher social comparison tendencies than participants in the control condition.

Given that self-activation has been found to increase people's interest in social comparison, the current study sought to investigate which effects it might have on women's vulnerability to media exposure. More specifically, it was examined whether manipulating levels of self-activation would make women feel less satisfied with their body after having been exposed to thin-ideal pictures. Two groups of women were compared: a group of body dissatisfied women who chronically attempt to restrict the amount they eat (i.e., restrained eaters; Herman \& Polivy, 1975; Lautenbacher et al., 1992) versus a group of body satisfied women who are not primarily focused on shape, weight, and dieting (i.e., unrestrained eaters). Both restrained and unrestrained eaters were randomly assigned to either a self-activation condition or a control condition (i.e., no selfactivation). It is expected that restrained eaters in a state of selfactivation will be more prone to the adverse effects of the media, as being aware of their present goals to meet a thin beauty standard will increase their tendency to compare themselves to other women. Therefore we hypothesize that self-activated restrained eaters will show a decrease in body and weight satisfaction after exposure to thin-ideal pictures compared to restrained eaters in the control condition. With regard to self-activated unrestrained eaters we expect no or less pronounced changes in body and weight satisfaction after thin-ideal exposure, as compared to unrestrained eaters in the control condition. Finally, it is hypothesized that participants in the self-activation condition will engage more in social comparison than participants in the control condition.

\section{Method}

\section{Participants}

A total of 79 female undergraduate students between the ages of 18 and $28(M=19.4, S D=1.74)$ participated in a study ostensibly testing the link between information processing and memory. Participants were divided into restrained and unrestrained eaters based on Restraint Scale (RS) cut-off scores as suggested by Herman and Polivy (1975). Participants with a score of 15 or higher classified as restrained eaters, whereas participants with a score below 15 classified as unrestrained eaters. Restrained eaters scored on average $18.45(S D=2.62)$ on the RS, whereas unrestrained eaters scored on average $7.54(S D=2.57)$ on the RS (normal scores for a Dutch sample, see also: Guerrieri, Nederkoorn, Schrooten, Martijn, \& Jansen, 2009). All participants (restrained and unrestrained) were randomly assigned to either the self-activation condition $(n=39)$ or the control condition $(n=40)$. All participants received a gift voucher or course credit for their participation. The present study was approved by the local committee for research ethics.

\section{Materials}

\section{Thin-ideal pictures}

In a pilot study a panel of 15 undergraduate students were asked to judge the attractiveness and slenderness $(0=$ least attractive - 10: most attractive) of 17 thin-ideal pictures, which were obtained from a Dutch modeling agency. Based on their judgments, eight full-body pictures with an average score of 9 on both attractiveness and slenderness were selected. All women on the thin-ideal pictures were models, wearing casual clothes. Next to each picture, information was given about the model (i.e., name, age, modeling agency). Participants were led to believe that they would get a memory test at the end of the experiment, and were instructed to carefully attend to the picture and description of every model. In the present study, participants were only exposed to thin-ideal pictures because these were documented to have the most negative effect on women's body image (for a review see: Groesz et al., 2002).

\section{Questionnaires}

Participants filled out Dutch versions of three questionnaires. (1) The Restraint Scale (RS; Herman \& Polivy, 1980) is an 11-item scale, which measures the extent to which participants try to restrain their food intake and show weight fluctuations. Scores range from 0 to 40 , with higher scores reflecting increased intention to restrain food intake. The Restraint Scale has acceptable internal consistency and test-retest reliability (Allison, Kalinsky, \& Gorman, 1992). Restraint scores were obtained through an undergraduate screening session at the beginning of the academic year. (2) State body satisfaction and state weight satisfaction were assessed using $100 \mathrm{~mm}$ Visual Analogue Scales (VAS) asking "how do you feel at this very moment about your body/weight", and ranging from 0 - "extremely dissatisfied" to 100 - "extremely satisfied". Participants had to indicate their answer by placing a vertical mark on the $100 \mathrm{~mm}$ scale. The body and weight satisfaction items were presented among a range of VAS filler items to disguise the purpose of the study. Visual analogue scales have been proven to be an effective assessment tool for reducing sensitization in experiments that involve rapid re-testing (Kazdin, 2003). Participants are less likely to remember their pretest answers at posttest on a VAS-scale than on a Likert-scale (Thompson, 2004). Body image VAS measures have high testretest reliabilities (Birkeland et al., 2005) and have been found to correlate highly (.68) with trait measures of body dissatisfaction (Garner, 1991; Heinberg \& Thompson, 1995). (3) Social comparison. Participants had to indicate on a $100 \mathrm{~mm}$ VAS to what extent ( $0=$ not at all, $100=$ very much) they had compared themselves with the models on the pictures while they were exposed to them (i.e., during the previous task, I compared myself (not at all - very much) with the models on the pictures. The social comparison items were presented among filler items. Finally, all participants were weighed and their height was measured to calculate Body Mass Index (BMI; weight in $\mathrm{kg} /$ height in $\mathrm{m}^{2}$ ).

\section{Manipulation}

\section{Self-activation manipulation before thin-ideal exposure}

In order to induce self-activation, participants were given an essay-assignment (Schwinghammer \& Stapel, 2006), which was presented as an application letter for a future employer. Participants were told that their application letter should enable their future employer to get an accurate impression of who they are and what they are capable of. In the essay-assignment participants were asked to describe three positive and three negative character traits of themselves in detail by (1) naming the traits and (2) referring to real-life situations illustrating these personal traits. In every sentence they had to use one of the following words: 'I', 'me', 'myself', or 'mine'. Control participants were given a neutral essay-assignment in which they had to write a short story (e.g., 7-10 sentences) about a chair and a table. They were instructed to use the following words in their description: 'chair', 'material', 'armrests', 'chair legs', 'table', and 'round'. 
Self-activation manipulation during thin-ideal exposure

To make sure that self-activation was maintained throughout the experiment we decided to use scrambled sentences (eight in total). After the presentation of each thin-ideal picture, participants were instructed to complete a scrambled sentence exercise. This exercise consisted of constructing a grammatically correct four-word sentence out of a five-word scrambled sentence. In the self-activation condition the scrambled sentences always contained the first-person pronoun 'I' (e.g., black I shoes like for), whereas the scrambled sentences in the control condition always contained third-person pronouns (i.e., names; e.g., black Billie shoes likes for).

\section{Self-activation manipulation check}

In order to check whether our self-activation manipulation had been effective, participants were asked to complete a selfactivation measure. Participants were presented with a short story in a non-existent language, in which 15 pronouns were underlined. They were told that the story they were presented with was written in Wezwe (i.e., a language only spoken in New Guinea), and they were instructed to guess the correct translation of each of the 15 pronouns (see Dijksterhuis \& van Knippenberg, 2000 for previous use of this task). For the translation, participants could choose from the following pronouns: 'he', 'his', 'she', 'her', 'you', 'yours', 'I', 'me', 'my'. The level of self-activation is indicated by the number of selected first-person pronouns. Previous research has shown that heightened self-activation leads participants to translate more pronouns as first-person pronouns (Dijksterhuis \& van Knippenberg, 2000; Stapel \& Tesser, 2001). To reassess the level of self-activation after participants were presented with the thin-ideal pictures (see procedure) and to avoid learning effects, we designed a Chinese symbol variant of the Wezwe task. The idea behind the Chinese symbol task was equal to the Wezwe task. The only difference was that in this task participants had to correctly guess the translation of 15 underlined Chinese symbols.

\section{Procedure}

Participants were invited to participate in a study ostensibly testing the link between information processing and memory. All participants were tested individually. After signing the informed consent, participants completed a pre-measurement of state body and weight satisfaction. Hereafter, participants were randomly assigned to either the self-activation condition or the control condition. In the self-activation condition, participants had to complete the self-activation essay-assignment. In the control condition participants had to complete the control essay-assignment. After this, all participants were given the Wezwe task (manipulation check). Subsequently, participants were exposed to eight thin-ideal pictures on a computer screen, which were presented as representing fashion models (eight pictures). Each picture was shown for $7 \mathrm{~s}$. After each picture a scrambled sentence exercise was presented. Participants were instructed to construct a four-word grammatically correct sentence out of five-word sequence, and were subsequently asked to read the sentence out loud. After the exposure, participants completed a postmeasurement of state body-and weight satisfaction. Furthermore, participants completed the social comparison VAS, in which they had to indicate to what extent they had compared themselves to the models during the exposure. After this, all participants completed the Chinese symbol task as a second manipulation check of self-activation. Then they were presented with five multiple-choice memory questions about the thin-ideal pictures to disguise the true purpose of the study. Next, the height and weight of all participants were recorded. Finally, participants were asked to write down their ideas about the true purpose of the study. All participants were debriefed in writing after all participants were tested.

\section{Results}

\section{Design and statistical analysis}

Results were analysed in a 2 (Condition: experimental vs. control) $\times 2$ (Group: restrained eaters vs. unrestrained eaters) ANCOVA with BMI and the pre-measurement of body and weight satisfaction (VAS) as covariates and the post-measurement of body and weight satisfaction (VAS) as dependent variables. Furthermore, a 2 (Condition: self-activation vs. control) $\times 2$ (Group: restrained eaters vs. unrestrained eaters) repeated measures ANOVA of the level of social comparison was conducted to determine whether the self-activation manipulation led to increased social comparison tendencies.

\section{Participant characteristics}

We conducted 2 (Group: restrained eaters vs. unrestrained eaters) $\times 2$ (condition: self-activation vs. control) analyses of Variance (ANOVA) to check for differences on age, BMI, and premeasurement of body and weight satisfaction. There were no significant condition effects, all $F s<1.09$, all $p s>.05$, and all $\eta_{p}^{2} \mathrm{~s}<.01$ However, we did find significant group effects for all variables, but age. Restrained and unrestrained eaters did not differ significantly on age but they did differ significantly with respect to BMI and pre-measurement of body and weight satisfaction. Restrained eaters had a significantly higher BMI and a lower bodyand weight satisfaction than unrestrained eaters, therefore these variables were used as covariates in the analyses of our main hypothesis. SeeTable 1 for means, $F$-values, and post hoc comparisons.

Taken together, restrained eaters were more dissatisfied with their body and had a higher BMI compared to unrestrained eaters.

Table 1

\begin{tabular}{|c|c|c|c|c|c|}
\hline \multirow[t]{3}{*}{ Measure } & \multicolumn{2}{|l|}{ Self-activation } & \multicolumn{2}{|l|}{ Control } & \multirow[t]{3}{*}{$F(1,75)$} \\
\hline & Restrained eaters & Unrestrained eaters & Restrained eaters & Unrestrained eaters & \\
\hline & $M(S D)$ & $M(S D)$ & $M(S D)$ & $M(S D)$ & \\
\hline Age (years) & $19.44(1.04)$ & $19.20(2.50)$ & $19.95(1.70)$ & $19.00(1.33)$ & 2.22 \\
\hline Restraint (RS) & $18.16(2.54)$ & $7.80(2.94)$ & $18.71(2.72)$ & $7.26(2.16)$ & $342.28^{*}$ \\
\hline BMI & $23.02(1.97)$ & $20.26(1.88)$ & $23.11(3.14)$ & $20.31(1.92)$ & $27.62^{*}$ \\
\hline Pretest Body satisfaction & $4.46(2.03)$ & $6.50(1.53)$ & $4.76(1.99)$ & $7.04(1.42)$ & $29.25^{*}$ \\
\hline Pretest Weight satisfaction & $3.78(1.92)$ & $6.77(2.02)$ & $4.18(2.12)$ & $7.04(1.59)$ & $45.14^{*}$ \\
\hline
\end{tabular}

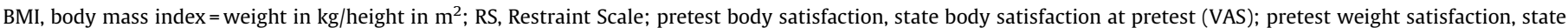
weight satisfaction at pretest (VAS). F-values are for the group effects.

$p<.001$. 
Manipulation check self-activation

To check whether the self-activation manipulation was successful, the use of first-person pronouns was counted. An independent samples $t$-test indicated that participants in the selfactivation condition used more first-person pronouns in the Wezwe task $(M=6.21, S D=1.72)$ than participants in the control condition $(M=5.23, S D=1.9), t(77)=2.39, p<.05, d=.55$. Furthermore, participants in the self-activation condition also used more first-person pronouns in the Chinese symbol variant of the Wezwe task $(M=6.15, S D=1.25)$ than participants in the control condition $(M=5.33, S D=1.23), t(77)=2.98, p<.01, d=.67$.

Taken together, these results indicate that the self-activation manipulation was successful at increasing levels of self-activation in the self-activation condition, as was apparent in both the Wezwe task and the Chinese symbol task.

\section{Social comparison}

A 2 (Condition: self-activation vs. control) $\times 2$ (Group: restrained eaters vs. unrestrained eaters) ANOVA of the level of social comparison, yielded a significant main effect of Condition, $F(1,75)=5.05, p<.05, \eta_{p}^{2}=.06$, indicating that participants in the self-activation condition showed higher levels of social comparison $(M=4.93, S D=2.52)$ than participants in the control condition $(M=3.69, S D=3.95)$. Furthermore, a significant main effect of Group, $F(1,75)=12.38, p<.01, \eta_{p}^{2}=.15$, was found. Restrained eaters compared themselves significantly more with the models $(M=5.20 ; S D=2.35)$ than unrestrained eaters $\operatorname{did}(M=3.65$; $S D=1.74)$. The Group $\times$ Condition interaction was non-significant, $F(1,75)=1.96, p=.16, \eta_{p}^{2}=.03$.

Taken together, these results indicate that participants in the self-activation condition had higher tendencies to socially compare themselves than participants in the control condition and that restrained eaters compared themselves more to the models than unrestrained eaters did.

\section{Self-activation, restrained eating, and body satisfaction}

A 2 (Condition: self-activation vs. control) $\times 2$ (Group: restrained eaters vs. unrestrained eaters) ANCOVA with BMI and the premeasurement of body- and weight satisfaction as covariates and the post-measurement of body satisfaction as dependent variable was conducted. With regard to the covariates, only the pre-measurement of body satisfaction was significant, $F(1,73)=228.86, p<.001$, $\eta_{p}^{2}=.76$. BMI was not significant, $F(1,73)=1.00, n s, \eta_{p}^{2}=.02$. Nonetheless, our findings yielded a significant main effect of Group, $F(1,73)=11.24, p<.01, \eta_{p}^{2}=.13$, and a significant main effect of Condition, $F(1,73)=5.83, p<.05, \eta_{p}^{2}=.07$. Of main interest to our hypotheses, these main effects were qualified by a significant Group $\times$ Condition interaction, $F(1,73)=9.73, p<.01, \eta_{p}^{2}=.12$. Simple effect analyses were conducted separately for the experimental and the control condition. In line with our hypothesis, there was only a significant main effect of Group in the experimental condition, $F(1,35)=30.21, p<.001, \eta_{p}^{2}=.46$, and not in the control condition, $F(1,35)=.17, n s, \eta_{p}^{2}=.01$. Furthermore, simple effects separately for the restrained and the unrestrained eaters yielded a significant main effect of Condition in the restrained group, $F(1$, $36)=15.25, p<.001, \eta_{p}^{2}=.30$, but not in the unrestrained eaters, $F(1,35)=0.24, n s, \eta_{p}^{2}=.01$. See Fig. 1 for mean scores of body satisfaction for the different groups and conditions.

\section{Self-activation, restrained eating, and weight satisfaction}

A 2 (Condition: self-activation vs. control) $\times 2$ (Group: restrained eaters vs. unrestrained eaters) ANCOVA with BMI and

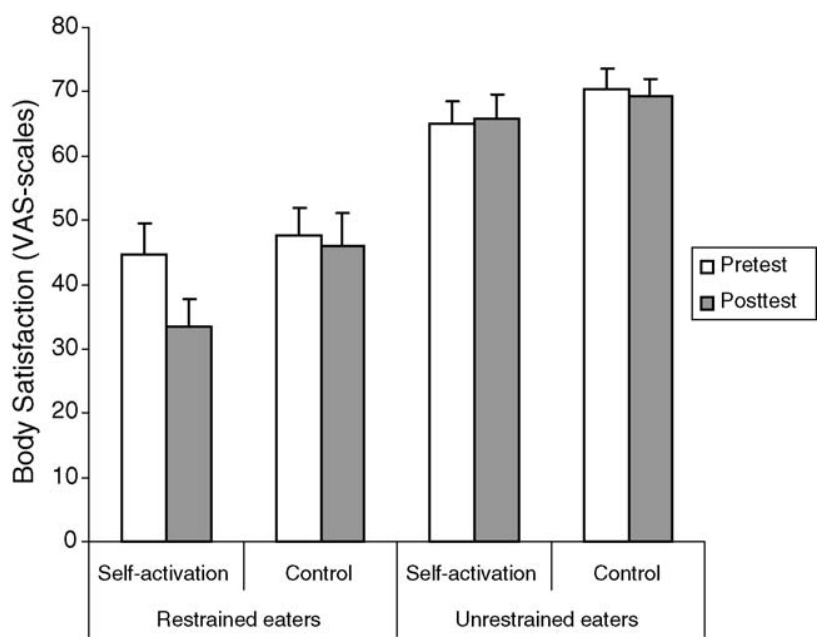

Fig. 1. Mean scores of body dissatisfaction at pre- and post-measurement for restrained and unrestrained eaters in the experimental and control condition.

the pre-measurement of weight satisfaction as covariates and the post-measurement of weight satisfaction as dependent variable was conducted. With regard to the covariates, only the pre-measurement of weight satisfaction was significant, $F(1,73)=269.30, p<.001$, $\eta_{p}^{2}=.79$. BMI was not significant, $F(1,73)=1.99, n s, \eta_{p}^{2}=.03$. Nonetheless, our findings yielded a significant main effect of Group, $F(1,73)=18.94, p<.001, \eta_{p}^{2}=.21$, and a significant main effect of Condition, $F(1,73)=10.67, p<.01, \eta_{p}^{2}=.13$. Of main interest to our hypotheses, these main effects were qualified by a significant Group $\times$ Condition interaction, $F(1,73)=9.45, p<.01, \eta_{p}^{2}=.12$. Simple effect analyses were conducted separately for the experimental and the control condition. In line with our hypothesis, there was only a significant main effect of Group in the experimental condition, $F(1,35)=30.60, p<.001, \eta_{p}^{2}=.47$, and not in the control condition, $F(1,35)=1.86, n s, \eta_{p}^{2}=.05$. Furthermore, simple effects separately for the restrained and the unrestrained eaters yielded a significant main effect of Condition in the restrained group, $F(1$, $36)=21.78, p<.001, \eta_{p}^{2}=.37$, but not in the unrestrained eaters, $F(1,35)=0.04, n s, \eta_{p}^{2}=.001$. See Fig. 2 for mean scores of weight satisfaction for the different groups and conditions.

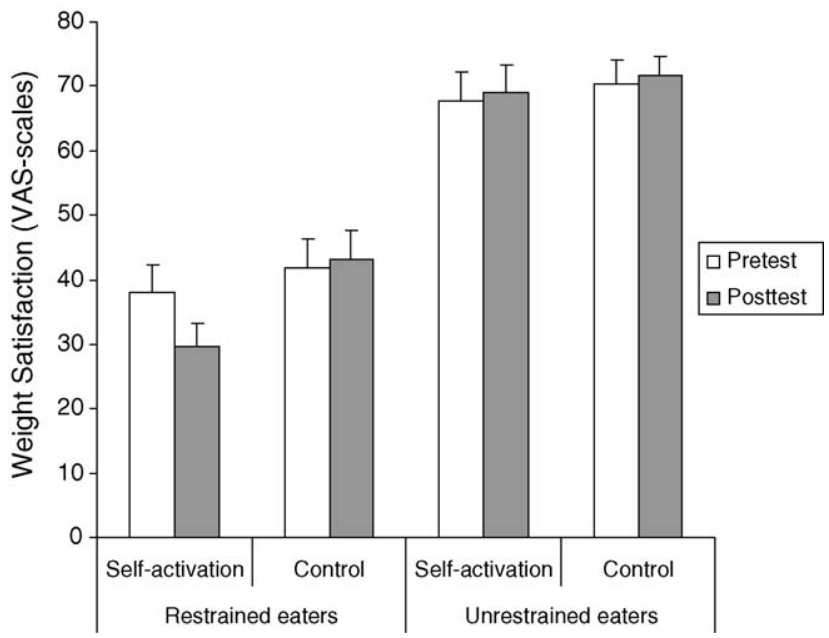

Fig. 2. Mean scores of weight dissatisfaction at pre- and post-measurement for restrained and unrestrained eaters in the experimental and control condition. 


\section{Mediating role of social comparison}

In order to investigate whether the effect of self-activation in restrained eaters may be mediated by social comparison, two 2 (Condition: experimental vs. control) $\times 2$ (Group: restrained eaters vs. unrestrained eaters) ANCOVAs with social comparison as covariate and the post-measurement of body and weight satisfaction as the dependent variables were conducted. With regard to the body satisfaction analysis, the social comparison covariate, $F(1,74)=12.38, p<.01, \eta_{p}^{2}=.14$, and the main effect of Group, $F(1,74)=30.81, p<.001, \eta_{p}^{2}=.29$, were found to be significant. The main effect of Condition, $F(1,74)=1.40$, $n s$, $\eta_{p}^{2}=.01$, and the Group $\times$ Condition interaction, $F(1,74)=0.42$, $n s, \eta_{p}^{2}=.00$, were not significant. With regard to the weight satisfaction analysis, the social comparison covariate, $F(1$, $74)=8.33, p<.001, \eta_{p}^{2}=.10$, and the main effect of Group, $F(1$, $74)=53.72, p<.001, \eta_{p}^{2}=.42$, were found to be significant. The main effect of Condition, $F(1,74)=1.79, n s, \eta_{p}^{2}=.03$, and the Group $\times$ Condition interaction, $F(1,74)=1.00$, $n s, \eta_{p}^{2}=.01$, were not significant. Taken together, the present analyses show that the interaction effect between Group $\times$ Condition disappeared when we controlled for the amount of social comparison during the manipulation. These findings suggest that the effect of selfactivation may be mediated by the amount of social comparison.

\section{Discussion}

In line with our hypothesis, it was found that restrained eaters in the self-activation condition felt less satisfied with their body and weight after exposure to thin-ideal pictures, as compared to restrained eaters in the control condition. Unrestrained eaters in the self-activation condition, however, did not experience any change in their body and weight satisfaction after exposure to the pictures, as compared to unrestrained eaters in the control condition. Taken together, these findings provide support for the potential negative influence of self-activation on body and weight satisfaction. Interestingly, the current data underline that exposure to thin-ideal images only had a negative influence on selfevaluations when two conditions were met: (1) when the participant was 'self-activated', and (2) when the participant classified as a restrained eater.

Results showed that our self-activation manipulation was successful at increasing levels of self-activation. Participants in the self-activation condition used more first-person pronouns in the Wezwe and Chinese symbol task than participants in the control condition. Furthermore, in addition to increasing levels of selfactivation, our self-activation manipulation also led to increased social comparison tendencies. Restrained participants and participants in the self-activation condition compared themselves significantly more with the thin-ideal pictures than unrestrained participants and participants in the control condition. This pattern of results suggested to us that the effect of self-activation in restrained eaters may be mediated by social comparison. This was indeed confirmed by mediation analyses in which the effect of selfactivation on body and weight satisfaction in restrained eaters disappeared when social comparison was controlled for. Thus, as the current goals and feelings of the restrained participants were made more accessible by the self-activation manipulation, they experienced an increased tendency to compare themselves with the thin models on the pictures, in turn causing them to feel less satisfied with their own body. Nevertheless, even though this explanation seems plausible, it warrants further exploration as we only included a state but not a trait measure of social comparison. The body image of restrained eaters in the control condition was left unaffected. This last finding is in line with findings from Jansen and de Vries (1995), who found that the subliminal presentation of the thin-ideal does not have a negative effect on women's body image.

The present pattern of results fits with research on social anxiety that has shown that self-focused attention can have negative effects for individuals with low self-confidence, whereas it has no or positive effects for individuals with high selfconfidence (e.g., Brockner \& Hulton, 1978; Duval \& Wicklund, 1972). As for self-activated unrestrained eaters, we found no changes in body and weight satisfaction after thin-ideal exposure compared with unrestrained eaters in the control condition. Even though self-activated unrestrained eaters did show increased tendencies to engage in social comparison, they were not at all influenced by the thin-ideal pictures that had been presented to them. These findings show that self-activation only has an adverse effect on restrained eaters.

Not only do the present results dovetail with previous research showing that not all women are equally vulnerable to the adverse effects of the media (Posavac et al., 1998; Tiggemann \& McGill, 2004; Trampe et al., 2007), they also extend previous knowledge on the factors that influence women's vulnerability to thin-ideal media images. Previous research has shown that women with high social comparison tendencies are more adversely influenced by thin-ideal images than other women. However, in the present study higher social comparison tendencies alone could not account for the negative effects of exposure thin-ideal images. Even though the selfactivation manipulation led to social comparison in both restrained and unrestrained eaters, only the restrained eaters were adversely affected by the thin-ideal images. The current data seem to suggest that exposure to thin-ideal images is not as detrimental as assumed before. Only a combination of a restrained eating style and an elevated state of self-activation made women feel less dissatisfied with their body and weight after being exposed to thin-ideal images.

The self-activation manipulation that was adopted in the current study provides a new and strictly implicit method for inducing social comparison tendencies in studies investigating the effects of thin-ideal images on body image. In line with Stapel and Tesser (2001), we showed that making people more aware of themselves by activating their self-related cognitions increases their interest in social comparison. Moreover, as none of the participants was able to guess the actual purpose of the study, it can be concluded that our self-activation manipulation was successful at preventing demand characteristics. In sum, this method might be valuable for future experimental research addressing the influence of social comparison on women's selfevaluations.

Even though the present study had a number of strengths, it also had a number of limitations. First, there might be an alternative explanation as to why the overall media effect obtained here might be weaker than mostly found in the literature. Our exposure procedure differed markedly from the usual media study in the re-priming of self-activation by the use of scrambled sentences between presentations of each thin ideal image. These scrambled sentences might have taken up additional cognitive capacity which might have distracted participants from the images, or which might have disrupted any cumulative effect from the thin-ideal images. Nevertheless, given that all conditions were presented with the scrambled sentences and given that we found a media effect in the self-activated restrained eaters, it seems that the distraction caused by the sentences was not strong enough to discard all the effects. It would, however, be of great interest to repeat the current research design without the repriming of self-activation during the thin-ideal exposure to make sure that the effects of the media are limited to self-activated restrained eaters. Second, even though our main analyses showed largely significant interaction effects, it must be noted that our sample sizes ( $n=20$ per condition) and effect sizes were rather 
modest. Future research using larger sample sizes is warranted to see whether the present findings can be replicated.

In conclusion, the present study presents preliminary evidence for the mediating role of self-activation and restraint status in explaining the adverse effects of the media on women's body image. Only restrained eaters who were more aware of themselves and who consequently engaged in more social comparison, showed a decrease in body and weight satisfaction after exposure to idealized images. These results are the first to draw attention to the importance of self-awareness and restraint status in explaining women's adverse reactions to idealized media images. As a combination of heightened self-awareness and restraint status might make women more vulnerable to the effects of the media, future research might try to implement attentional retraining strategies which teach women to focus less on themselves. Attentional retraining has been proven to be successful in treating individuals with social anxiety disorder (Schmidt, Richey, Buckner, \& Timpano, 2009) and generalized anxiety disorder (Amir, Beard, Burns, \& Bornyea, 2009). In this respect, it would be worthwhile to investigate whether this technique might also be helpful for decreasing women's vulnerabilities to the effects of thin-ideal exposure.

\section{References}

Allison, D. B., Kalinsky, L. B., \& Gorman, B. S. (1992). A comparison of the psychometric properties of three measures of dietary restraint. Psychological Assessment, 4, 391398.

Amir, N., Beard, C., Burns, M., \& Bornyea, J. (2009). Attention modification program in individuals with generalized anxiety disorder. Journal of Abnormal Psychology, 118 , 28-33.

Bearman, S. K., Presnell, K., Martinez, E., \& Stice, E. (2006). The skinny on body dissatisfaction: A longitudinal study of adolescent girls and boys. Journal of Youth and Adolescence, 35, 229-241.

Brockner, J., \& Hulton, A. J. (1978). How to reverse the vicious cycle of low self- esteem: The importance of attentional focus. Journal of Experimental Social Psychology, 14, 564-578.

Cattarin, J. A., Thompson, J. K., Thomas, C., \& Williams, R. (2000). Body image, mood, and televised images of attractiveness: The role of social comparison. Journal of Social and Clinical Psychology, 19, 220-239.

Corning, A. F., Krumm, A. J., \& Smitham, L. A. (2006). Differential social comparison processes in women with and without eating disorder symptoms. Journal of Counseling Psychology, 3, 338-349.

Dijksterhuis, A., \& van Knippenberg, A. (2000). Behavioral indecision: Effects of self focus on automatic behavior. Social Cognition, 18, 55-74.

Dittmar, H., \& Howard, S. (2004). Thin-ideal internalization and social comparison tendency as moderators of media models' impact on women's body-focused anxiety. Journal of Social and Clinical Psychology, 23, 768-791.
Duval, S., \& Wicklund, R. A. (1972). A theory of objective self-awareness. New York: Academic Press.

Festinger, L. (1954). A theory of social comparison processes. Human Relations, 7. $117-140$.

Garner, D. M. (1991). Eating Disorder Inventory-2. Odessa, FL: Psychological Assessment Resources.

Grabe, S., Ward, L. M., \& Hyde, J. S. (2008). The role of media in body image concerns among women: A meta-analysis of experimental and correlational studies. Psychological Bulletin, 134, 460-476.

Groesz, L. M., Levine, M. P., \& Murnen, S. K. (2002). The effect of experimental presentation of thin media images on body satisfaction: A meta-analytic review. International Journal of Eating Disorders, 31, 1-16.

Guerrieri, R., Nederkoorn, C., Schrooten, M., Martijn, C., \& Jansen, A. (2009). Inducing impulsivity leads high and low restrained eaters into overeating, whereas current dieters stick to their diet. Appetite, 53, 93-100.

Heinberg, L. J., \& Thompson, J. K. (1995). Body image and elevised images of thinness and attractiveness: A controlled laboratory investigation. Journal of Social and Clinical Psychology, 14, 325-328.

Herman, C. P., \& Polivy, J. (1975). Anxiety, restraint, and eating behavior. Journal of Abnormal Psychology, 84, 666-672.

Herman, C. P., \& Polivy, J. (1980). Restrained eating. In A. J. Stunkard (Ed.), Obesity (pp. 208-225). Philadelphia: Saunders.

Jansen, A., \& de Vries, M. (1995). Pre-attentive exposure to the thin female beauty does not affect women's mood; self-esteem and eating behaviour. European Eating Disorders Review, 10, 208-217.

Kazdin, A. E. (2003). Drawing valid inferences Internal and external validity, Research design in clinical psychology, (4th ed.). Boston, MA: Allyn \& Bacon. pp. 22-53.

Lautenbacher, S., Thomas, A., Roscher, S., Strian, F., Pirke, K. M., \& Krieg, J. C. (1992) Body size perception and body satisfaction in restrained and unrestrained eaters. Behavior Research and Therapy, 30, 243-250.

Posavac, H. D., Posavac, S. S., \& Posavac, E. J. (1998). Exposure to media images of female attractiveness and concern with body weight among young women. Sex Roles, 38 187-201.

Schmidt, N. B., Richey, J. A., Buckner, J. D., \& Timpano, K. R. (2009). Attention training for generalized social anxiety disorder. Journal of Abnormal Psychology, 118, 5-14.

Schwinghammer, S. A., \& Stapel, D. A. (2006). The effects of different types of selfactivation on social comparison orientation. Social Cognition, 24, 703-722.

Stapel, D. A., \& Tesser, A. (2001). Self-activation increases social comparison. Journal of Personality and Social Psychology, 81, 742-750.

Stormer, S. M., \& Thompson, J. K. (1996). Explanations of body image disturbance: A test of maturational status, negative verbal commentary, social comparison, and sociocultural hypotheses. International Journal of Eating Disorders, 19, 193-202.

Stice, E., Schupak-Neuberg, E., Shaw, H. E., \& Stein, R. I. (1994). Relation of media exposure to eating symptomatology: An examination of mediating mechanisms. Journal of Abnormal Psychology, 103, 836-840.

Stice, E., \& Whitenton, K. (2002). Risk factors for body dissatisfaction in adolescent girls: A longitudinal investigation. Developmental Psychology, 38, 669-678.

Tiggemann, M., \& McGill, B. (2004). The role of social comparison in the effect of magazine advertisements on women's mood and body dissatisfaction. Journal of Social and Clinical Psychology, 23, 23-44.

Thompson, J. K. (2004). The (mis)measurement of body image. Body Image: An International Journal of Research, 1, 7-14.

Trampe, D., Stapel, D. A., \& Siero, F. W. (2007). On models and vases: Body dissatisfaction and proneness to social comparison effects. Journal of Personality and Social Psychology, 92, 106-118. 